\title{
Study on the Bearing Mode and Force Transfer Path of Composite Bucket Foundations
}

\author{
Shaohua He ${ }^{2}$, Puyang Zhang ${ }^{1,2, *}$ and Hongyan Ding ${ }^{1,2}$ \\ 1 State Key Laboratory of Hydraulic Engineering Simulation and Safety, Tianjin University, Tianjin 300072, \\ China; dhy_td@163.com \\ 2 School of Civil Engineering, Tianjin University, Tianjin 300072,China; hsh_td@163.com \\ * Correspondence: zpy@tju.edu.cn
}

Academic Editor: Lance Manuel

Received: 13 June 2017; Accepted: 18 July 2017; Published: 20 July 2017

\begin{abstract}
This paper elaborates on a new composite bucket foundation (CBF) structural system for offshore wind turbines. The proposed CBF consists of a special force transition section, a beam system structure upper steel bucket cover and a large-scale steel bucket with honeycomb structure rooms. It can be prefabricated onshore, self-floated on the sea and then towed to the appointed sea area before sinking to the sea soil under negative pressure. This is called the "one-step" installation technology. Arc- and line-type bucket foundations are calculated by both theory and the finite element method to discuss their force transfer paths and bearing modes. Owning to the special structural form, the transition section can effectively convert the huge load and bending moment into controllable tension and compressive stress, as well as adjust the structure balance. The bearing model and percentage of each part of the composite foundation under monotonous and ultimate load conditions are also calculated. Results indicate that the bearing mode of CBF is a typical top cover mode. In addition, the curvature impact of arc-type is studied and the results reveal that the structure type of the transition section is more important than the diameter ratio between the bottom transition section and the bucket.
\end{abstract}

Keywords: wind energy; composite bucket foundation; transfer segment; load transfer characteristic; bearing mechanism

\section{Introduction}

Offshore wind turbines are a new frontier in wind power development. Their foundations are significantly affected by the horizontal force and large bending moment at the top. Considering the mechanical properties, cost-effectiveness, and construction feasibility, the main forms of offshore wind turbine structures usually consist of concrete structures, such as elevated pile caps, monopile foundations, and gravity foundations. Bucket foundations are a new type of foundation currently used in offshore wind power construction. They are also called suction anchors, because they used to be applied to the mooring system as a suction pile. The bucket foundation looks like an inverted cup that is closed at the top and opened at the bottom. Steel bulkheads divide the seven rooms inside the composite bucket foundation (CBF). Hence, it is a relatively special construction layout, whose main mechanism is based on the principle of negative pressure penetration.

In recent years, studies on bucket foundations have been carried out in China and abroad. Helfrich et al. [1] first carried out a model test in sand to study the characteristics and failure modes of suction anchors, and provided test data associated with a 400-mm diameter suction anchor. Le et al. [2] presented the bearing capacities of bucket foundations in normally consolidated uniform clay under undrained conditions, and reported that the vertical capacity consisted of an end-bearing resistance and a skin friction resistance, whereas the horizontal capacity consisted of a normal resistance, a radial 
shear resistance, and a base shear resistance. Barari et al. [3] proposed a new equation for calculating the horizontal and vertical bearing capacities. Moreover, they carried out an experiment of moment loading on small-scale ( $30 \mathrm{~cm}$ diameter) bucket foundation models installed on Yoldia clay, and presented the yield loci to describe the load combinations at failure in the horizontal, vertical, and moment loading coordinate system $(H-V-M)$. Park et al. [4] conducted a two-dimensional (2D) axisymmetric finite element simulation to investigate the vertical load transfer mechanism of a bucket foundation installed in sand, indicating that the calculated bearing capacity of bucket foundation was larger than the sum of the end-bearing capacity of shallow foundation and the skin friction of pile [5]. Meanwhile, Kim et al. [5] conducted numerical analyses and three centrifugal tests to investigate the behavior of a suction anchor in cohesionless soil. Vahdatirad et al. [6] introduced a load-displacement-based approach to assess the bearing capacity and the deformation of a mono-bucket foundation subjected to combined loading, presented a p-y curve to quantify the lateral soil response around the foundation and compared those with the field test results for a bucket foundation installed in sandy and silty soil. Lian et al. [7] analyzed a pre-stressed bucket foundation to discuss the characteristics of an arc-type transition part with 40-60 channels arranged with pre-stressed steel strands under the same boundary conditions and ultimate load. Zhang et al. [8] conducted a test on muddy soil reinforcement by negative pressure and electro-osmosis inside a cover-bearing-type bucket foundation for offshore wind turbines, compared the results obtained by using the electro-osmotic and negative pressure methods, and obtained the most reasonable current value for scale model testing. Li et al. [9] conducted finite element and experimental analyses on the bearing capacities of modified suction caissons in saturated marine fine sand under a static horizontal loading condition, and reported the relationship between the location of rotation center and external skirt dimensions, and proposed an expression for estimating the combined capacity. In 2014, Liu et al. [10] set up a three-dimensional (3D) finite element model (FEM) to define the failure mode of a wide-shallow bucket foundation by calculating the shape of the yield envelope of the bucket foundation in the $V-H, V-M, H-M$, and $V-H-M$ spaces. Ding et al. [11] conducted several field tests on the horizontal bearing capacity of CBF in saturated clay off the coast of China, revealing the soil-structure interaction, deformation mechanism, and the ultimate bearing capacity of CBF. Moreover, they described the envelope curve of the ultimate bearing capacity of the $\mathrm{CBF}$ in the $H-M$ load space, thus clarifying the load-bearing characteristics of $\mathrm{CBF}$ under combined loads. In 2015, Liu et al. [12] performed a model test to observe the vertical bearing capacity of composite bucket shallow foundation, and also employed a new empirical parameter to describe the soil damage rate and discussed the relationship of friction angle with the bearing capacity factors at specific soil damage rates.

In one word, scholars have mainly focused on proposing methods for calculating the bearing capacity, suction penetration mechanism, and the failure mode of various loads. Discriminant and calculation methods were also proposed to define the bearing capacities of different bucket foundations and their failure mechanisms [13-21]. However, the studies mentioned above are mostly based on traditional bucket foundations with small diameters, and research on new and large-scale CBFs is relatively scarce.

Large-scale CBF systems for offshore wind turbines have been an ongoing study topic for the offshore wind group at Tianjin University (China) $[17,19,20,22,23]$. At present, the preliminary project has been completed, and the prototype test has already been carried out. Figure 1 presents the images of the offshore test facility located in Qidong (Jiangsu Province, China). Figure 2c shows the difference between the traditional bucket foundation and the new CBF. The overall structural system mainly consists of the upper transition section (yellow part shown in Figure 1), a beam-slab system on the top cover, and the steel cylinder with honeycomb rooms, whose bucket is a large cylindrical structure that is opened at the bottom and closed at the top. The cylindrical part is denoted as the bucket skirt, and the upper plate that closes the bucket is denoted as the bucket lid. The entire composite bucket has a clear wall height of $12 \mathrm{~m}$ and a diameter of $30 \mathrm{~m}$. At present, two forms of transition sections are considered: arc- and line-type. The offshore wind turbine foundation is subjected to huge 
horizontal load and bending moment, and in actual designs, it must find a reasonable structural form to effectively transfer loads to the seabed soil through the cooperation of each part.

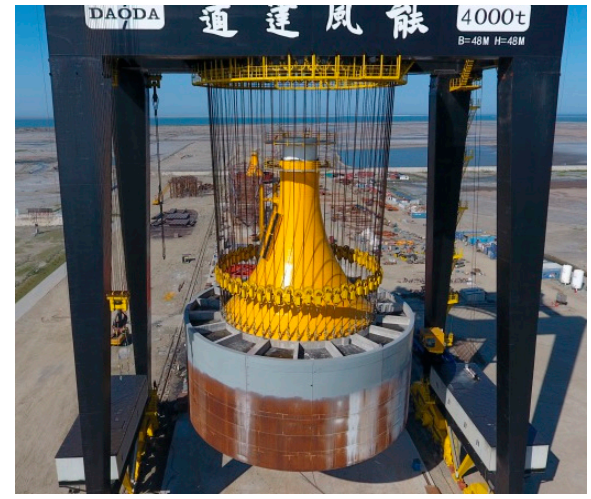

(a)

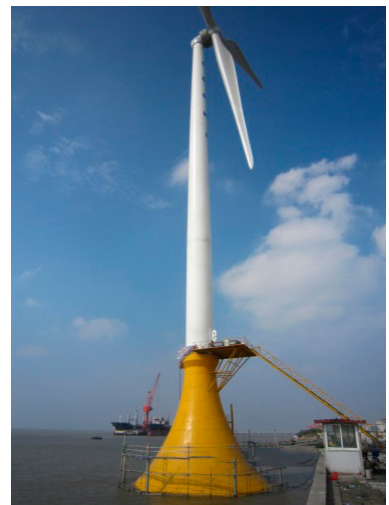

(b)

Figure 1. Pictures of the composite bucket foundation in China: (a) Transition section; (b) Offshore wind turbine with $\mathrm{CBF}$.

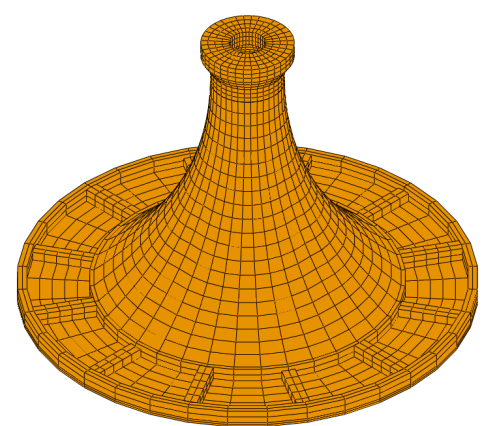

(a)

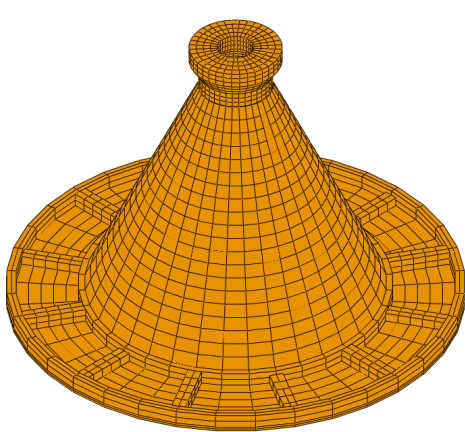

(b)

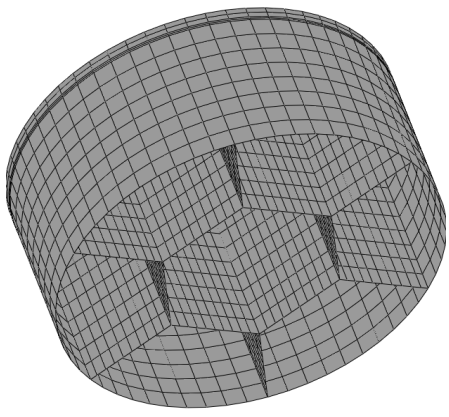

(c)

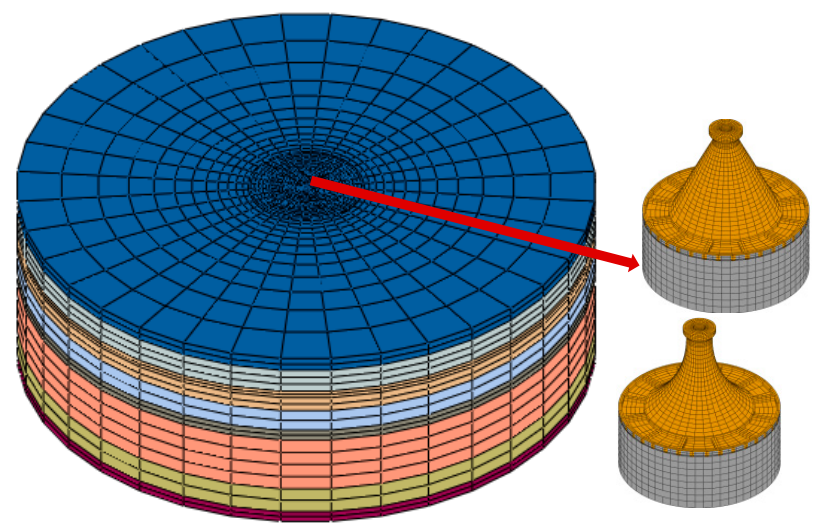

(d)

Figure 2. ABAQUS computation model: (a) Arc transmission section; (b) Line transmission part; (c) Bucket with subdivision plates; (d) Soil and foundation model.

In this paper, a numerical 3D FEM based on engineering practices in China was set up to investigate the load transfer characteristics, bearing modes, and the contribution of each part of the composite foundation under monotonous and ultimate load conditions. The impact of arc-type curvature was also studied. 


\section{Finite Element Models of Two Typical Foundations}

The CBF for offshore wind turbines consists of an upper transition section, a beam-slab structure, and a steel bucket with honeycomb skirt, which includes a concrete transition segment of hollow thin-walled structures, as shown in Figure 2. According to the upper transition section structure, two different foundations are used in the project: arc-type (Figure 2a) and line type (Figure 2b). The CBFs have a clear wall height of $12 \mathrm{~m}$ and an outer diameter of $30 \mathrm{~m}$, including a magnified area that is $3 \mathrm{~m}$ high on the top. The wall thickness $(T)$ of hollow thin-walled transfer segment is $0.6 \mathrm{~m}$, the center distances on the top opening $\left(D_{1}\right)$ and bottom $\left(D_{2}\right)$ are $4.4 \mathrm{~m}$ and $19.5 \mathrm{~m}$, respectively. The arc transition section has a curvature radius $(R)$ of $21.7 \mathrm{~m}$, and the entire transition section height $H_{1}$ is $19.8 \mathrm{~m}$. The main and secondary beams are arranged in the radial direction; the cross-section heights of the main beam and the secondary beam are $0.9 \mathrm{~m}$ and $0.6 \mathrm{~m}$, respectively. The slab on the top cap is a concrete structure with a thickness of $0.3 \mathrm{~m}$. Moreover, the composite bucket has a height $\left(\mathrm{H}_{2}\right)$ of $12 \mathrm{~m}$ and a diameter $(D)$ of $30 \mathrm{~m}$. In this model, the ratio between $D_{2}$ and $D$ is 0.65 . The overall FEM is shown in Figure 2.

The CBF system has a complex shape, which makes it difficult to determine the transfer characteristics and bearing mechanism in layered soil. A 3D FEM is established by using ABAQUS, and both the pre-stressed and non-pre-stressed models are considered.

The transition section and beams are made of concrete C50, with a characteristic strength of 50 MPa. The concrete, steel bucket skirt and subdivision plates are assumed to form an ideal elastoplastic model. The Young's modulus of the concrete is $34.5 \mathrm{GPa}$ and that of steel is $206 \mathrm{GPa}$. The Poisson's ratio of steel is 0.3 and that of concrete is 0.17 . The two types of pre-stressed transition section consist of the same steel strand and tension control stress of $1320 \mathrm{MPa}$. The number of pre-stressed channels along the circumference is 48 , and each layer is $24 \mathrm{~m}$ in thickness along the wall. Each channel has 11 steel strands consisting of seven pre-stressed steel wires; the corresponding Young's modulus is $2.0 \times$ $10^{5} \mathrm{MPa}$, and the yield strength is $1860 \mathrm{MPa}$.

The geological conditions at the present and potential future sites for offshore wind farms in China, which feature silty sands, silty clays, muddy silty clays, etc., are complex. The typical soil used in this paper is from a planned wind farm site located off the coast of Jiangsu Province. Based on the soil test results listed in Table 1, the height of the soil is $150 \mathrm{~m}$ and the diameter is $50 \mathrm{~m}$; the soil is modeled as an elastic-plastic model according to the Mohr-Coulomb failure criterion.

Table 1. Soil properties.

\begin{tabular}{|c|c|c|c|c|c|c|}
\hline Soil Layers & $\begin{array}{c}\text { Thickness } \\
\text { (m) }\end{array}$ & $\begin{array}{c}\text { Effective } \\
\text { Density }\left(\mathrm{kg} / \mathrm{m}^{3}\right)\end{array}$ & $\begin{array}{l}\text { Compression } \\
\text { Modulus (Mpa) }\end{array}$ & $\begin{array}{l}\text { Poisson's } \\
\text { Ratio }\end{array}$ & $\begin{array}{l}\text { Cohesion } \\
\text { (kPa) }\end{array}$ & $\begin{array}{c}\text { Internal } \\
\text { Friction (deg) }\end{array}$ \\
\hline Silty sand & 3.6 & 980 & 9.04 & 0.25 & 11.0 & 29.0 \\
\hline Muddy silty clay & 6.4 & 780 & 3.13 & 0.39 & 14 & 12.1 \\
\hline Silt & 2 & 1030 & 13.06 & 0.21 & 4.4 & 33.5 \\
\hline Silty clay & 4 & 890 & 3.83 & 0.37 & 21.8 & 13.7 \\
\hline Silty sand & 6 & 980 & 15.04 & 0.25 & 21.4 & 29.6 \\
\hline Silt & 3 & 960 & 13.03 & 0.22 & 4.7 & 33.2 \\
\hline Silt clay & 15 & 960 & 5.70 & 0.25 & 38.5 & 17.8 \\
\hline Silty clay & 7 & 1050 & 11.22 & 0.25 & 10.8 & 29.1 \\
\hline
\end{tabular}

For convenience, the soils are all simulated by a standard element of C3D8R. The contact pair algorithm in ABAQUS is employed to simulate the contact features of the interface between the foundation and soil, and the friction coefficient is 0.35 . To estimate the tangential ultimate frictional resistance, Coulomb's friction law is used. The foundation and soil are tied together, thus no slip will occur when the shear stress on the contact surface is less than the ultimate frictional resistance. The bottom surface of soil is subjected to the constraint of fixed end and the normal constraint is applied to the lateral boundary. Prior to loading, stress balance is eliminated, and the additional deformation due to the gravity of structure is eliminated. 


\section{Analysis of the Force Transfer Characteristics of Bucket Foundations}

From the mechanical perspective, the main load transfer to the top of transition section is bending moment $(M)$, horizontal load $(H)$, and vertical load $(V)$. The combination of loads is a simplified calculation under various load conditions. A simplified structure is necessary when performing structural analysis and design. Therefore, beam theory is used to calculate the transfer segment during the design. The load conversion diagram of the transition section under external load is shown in Figure 3.

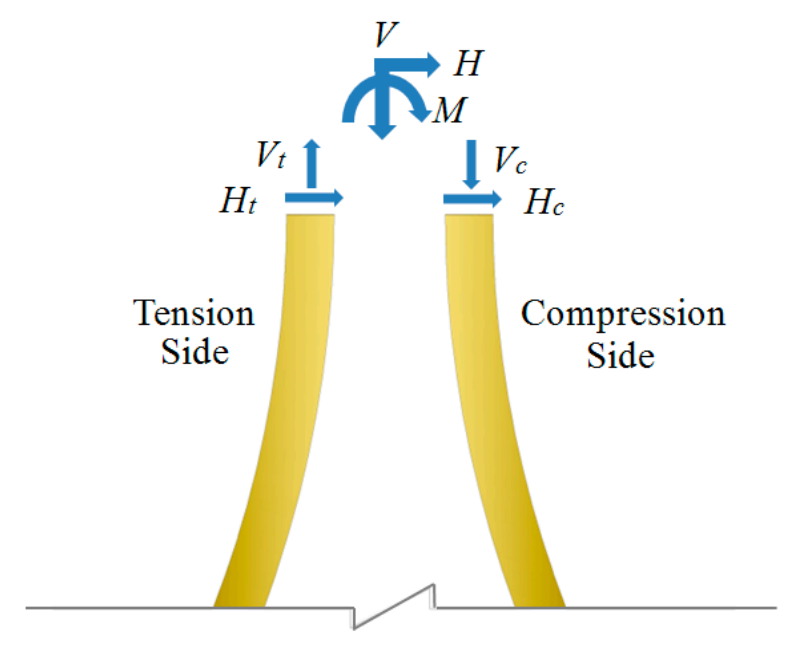

Figure 3. Schematic diagram of the load transfer.

As shown in Figure 3, under composite loads, the transfer section is compressed on one side and tensile on the other. The external load is converted to horizontal or vertical force alone or into a combination of both of them on the transfer section. The calculation methods are presented below.

For vertical force only, the maximum normal stress of each cross-section is:

$$
\sigma_{C, \max }=\frac{V}{A}
$$

For bending moment only, the maximum normal stress of each cross-section is:

$$
\sigma_{M, \max }=\frac{M y_{\max }}{I_{x}}
$$

where $y_{\max }$ represents the outer radius of each cross-section.

The second moment of the transfer segment is given by:

$$
I=\frac{\pi\left(d_{1}^{2}-d_{2}^{2}\right)}{64}
$$

where $d_{1}$ is the outer diameter of the section, $d_{2}$ is the inner diameter of the section, $t$ is the thickness of the transition section, and $A$ is the circular cross-section area.

The internal force of each cross-section is respectively calculated, as shown in Figure 4. 


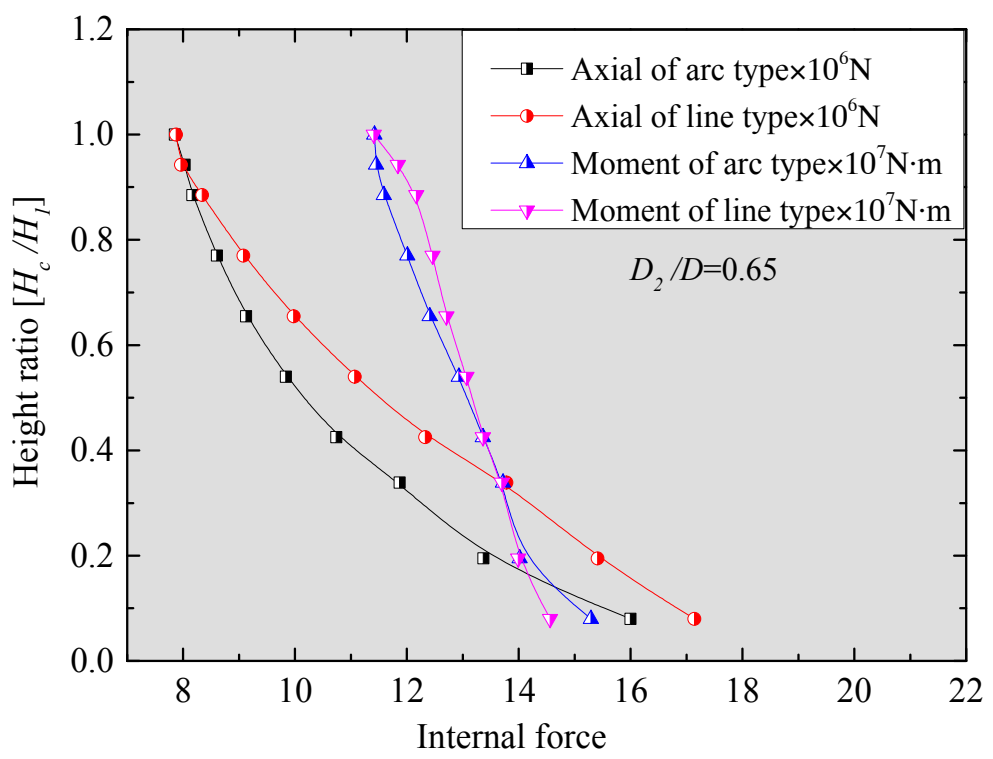

Figure 4. Cross-section of the internal force.

The CBF transition section is located in sea water. For the concrete transfer section, when concrete cracking occurs in the tensile zone, the compressive strength of concrete does not reach the design value, indicating that the structure is already facing the threat of corrosion. Hence, in order to adjust the tension and compression force balance as well as to prevent the occurrence of cracks, the transition section should be designed as a pre-stressed structure. The vertical force on each cross-section of the transition segment is primarily generated by the pre-stressed tendons.

The compressive stress on each cross-section of the transition section resulting from the pre-stressed tendons is given by:

$$
\sigma_{P}=\frac{F_{p}}{A}
$$

where $F_{p}$ is the resultant force produced by the pre-stressed tendons, and $A$ is the area of each cross-section.

According to the above calculations, the tensile and compressive stress of each cross-section under the combined action of a bending moment and the pre-stressed steel are respectively given by:

$$
\begin{gathered}
\sigma_{T, \text { max }}=\sigma_{M, \text { max }}-\sigma_{P} \\
\sigma_{C, \text { max }}=\sigma_{M, \text { max }}+\sigma_{P}
\end{gathered}
$$

where $\sigma_{C, \max }$ is the max stress on compressive side of cross-section, and $\sigma_{T, \max }$ is the max stress on tension side of cross-section.

The maximum compressive and tension stress of the two types of CBF under the ultimate load of 50-year return periods are shown in Figure 5a,b, respectively. As shown in Figure 5a, the line- and arc-type have significantly different force transfer characteristics, showing that the compressive and tensile stresses are greatest at the top of the transfer segment. The tensile stresses of the non-pre-stressed arc and line structures are approximately $14.5 \mathrm{MPa}$ and 13.2 Mpa, respectively, and the compressive stresses are approximately $15.5 \mathrm{MPa}$ and $16.9 \mathrm{MPa}$, respectively. On the tension side, the maximum stress on each section exceeds the ultimate strength of C50 concrete. Meanwhile, the stress does not reach the limit value on the compression side of the transition section. As shown by the curve of the pre-stressed model, the peak tensile stresses on each section of line-type and arc-type are less than the limit value of 1.89 MPa. Most cross-section stresses of line-type are even close to zero. Meanwhile, the compression stresses on each section of the pre-stressed model increases, but they are always lower 
than the limit value. For the line-type, the compression stresses on each section of arc-type are less than the limit value of $23.1 \mathrm{MPa}$.

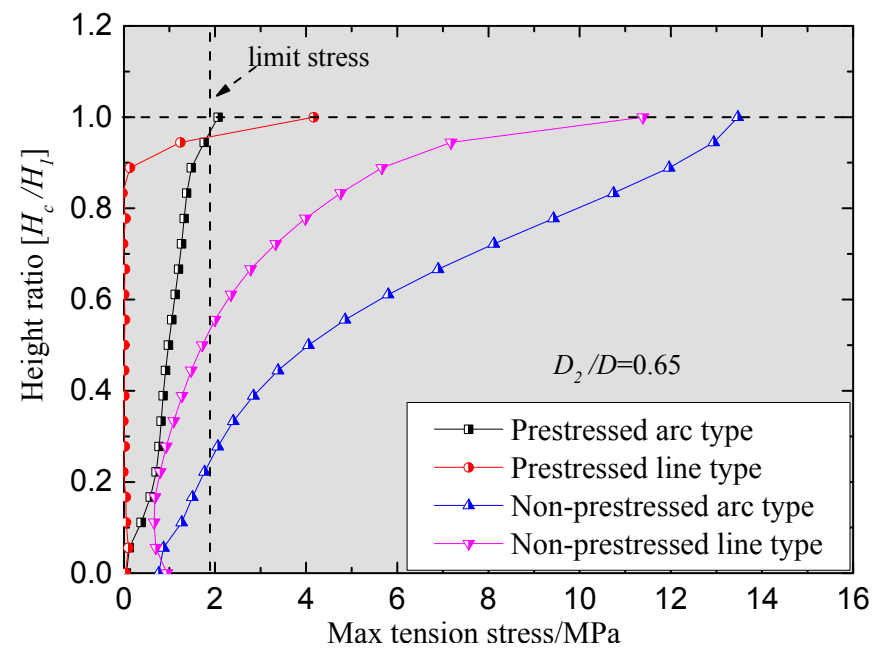

(a)

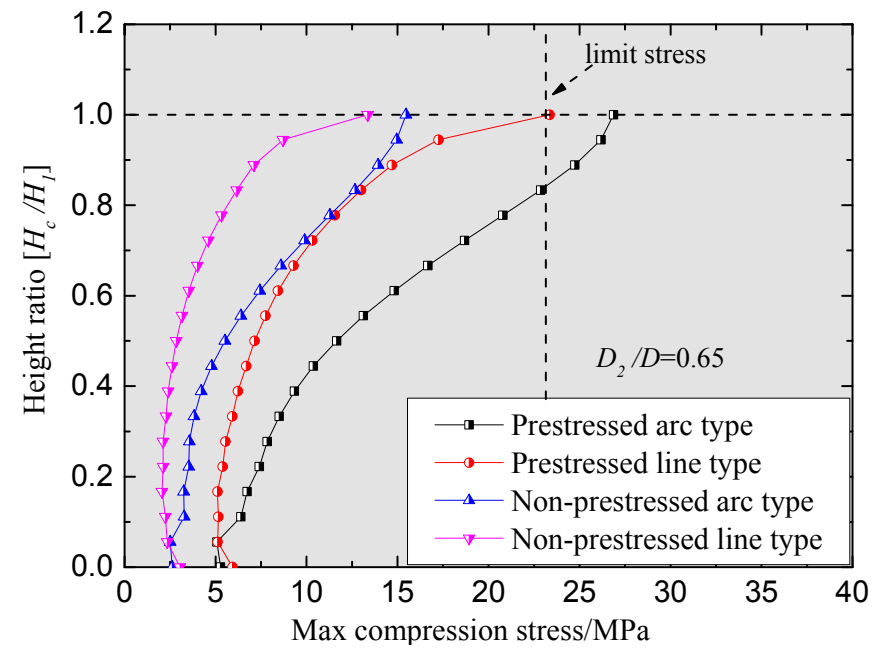

(b)

Figure 5. The cross-section stress ultimate load condition: (a) Maximum stress of the tension side; (b) Minimum stress of the compression side.

For the arc-type, the compression stress increase ratio is $49 \%$, and the average tension stress reduction ratio is $78 \%$. For the line-type, the corresponding values are $55 \%$ and $93 \%$, respectively.

The tension and compression stress distribution results calculated by FEM are shown in Figures 6 and 7. Both regulations between the pre-stressed line and arc-type or the non-pre-stressed model can be clearly seen, which are essentially consistent with the calculation results shown in Figure 5. The pre-stressed line-type has better load-bearing performance than the arc one; the former can also maintain a lower stress level in most cross-sections throughout the entire transitional segment, except at the top. Therefore, the line structure has better capability to resist cracks. Owing to the special structural form, the arc structure can help gradually diffuse and distribute stress along the height and circumferential directions. 


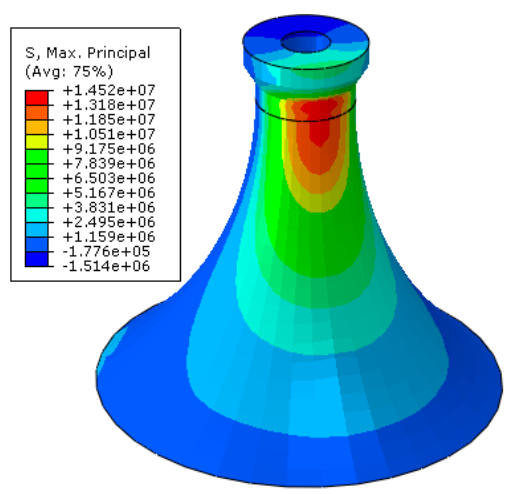

(a)

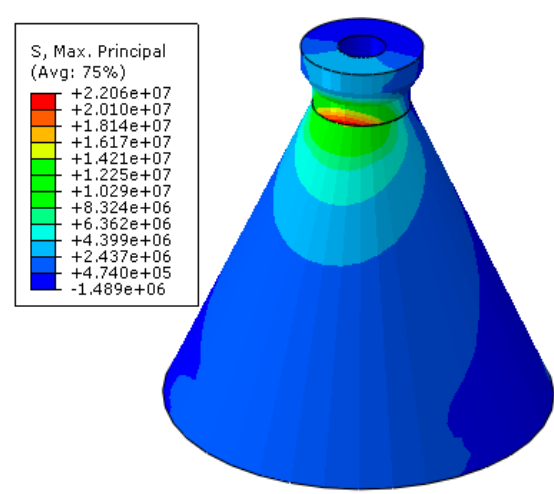

(b)

Figure 6. Stress transfer of the non-pre-stressed part. Stress transfer of the pre-stressed part: (a) Arc type; (b) Line type.

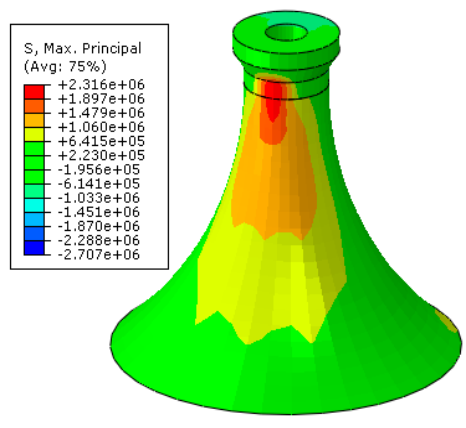

(a)

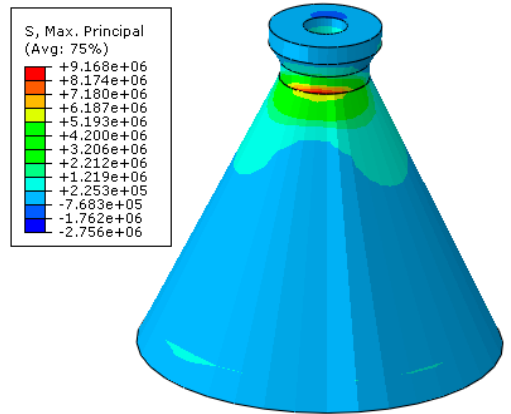

(b)

Figure 7. Stress transfer of the pre-stressed part: (a) Arc type; (b) Line type.

In contrast, both transitional segments can gradually transfer the huge bending moment load downwards at the upper structure of the turbine with the pre-stressed tendons until the load becomes relatively smaller, and further changes into controllable tensile and compressive stresses. However, the section area of line-type is larger than that of arc-type at the same height, representing one disadvantage of wave loading diffraction theory.

Figure 8 shows the computation results of equivalent plastic strain under ultimate load condition. When the equivalent plastic strain is larger than 0 , the soil will yield. Figure 9 shows the displacement distribution field of two kinds of foundation under ultimate load condition, illustrating that the two failure modes are essentially similar, i.e., the failure region first occurs in front of the bucket wall and then extends along the loading direction to the bottom of the bucket. The failure modes include wedge-shaped failure and sliding-shear failure. In addition, the plastic strain area of line-type is slightly larger than that of arc-type; their maximum values are $8.41 \times 10^{-2}$ and $8.08 \times 10^{-2}$, respectively. As can be seen from Figure 9, under combined loading, as the load increases, the deformations of arc- and line-type are also the same, which further develop to a rotational failure. The deformation of line-type is relatively larger than that of arc-type; their maximum values are $62.82 \mathrm{~mm}$ and $69.92 \mathrm{~mm}$, respectively. The line foundation transfers more loads to the soil, and a wider soil area around the foundation is involved in load bearing. According to the design provisions of wind turbine foundation, the CBF of $3 \mathrm{MW}$ has a limit tilt rate of 3\%, and a settlement value of $100 \mathrm{~mm}$. In summary, the line composite bucket shows better performance in terms of deformation control and transmission mechanism. 


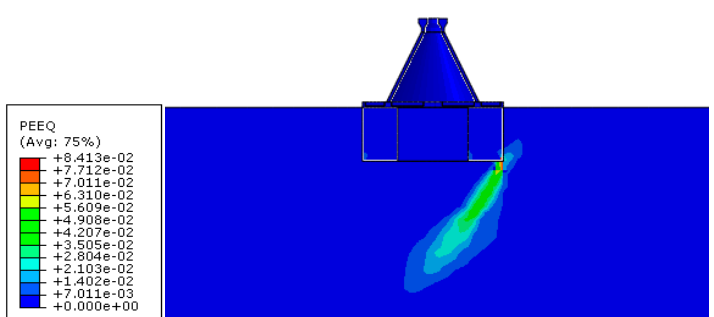

(a)

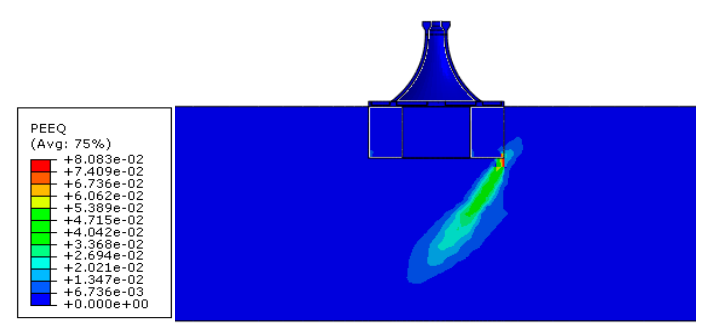

(b)

Figure 8. Equivalent plastic strain under ultimate load: (a) Line type; (b) Arc type.

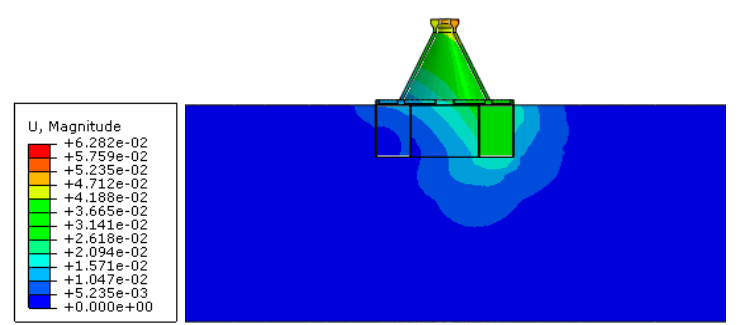

(a)

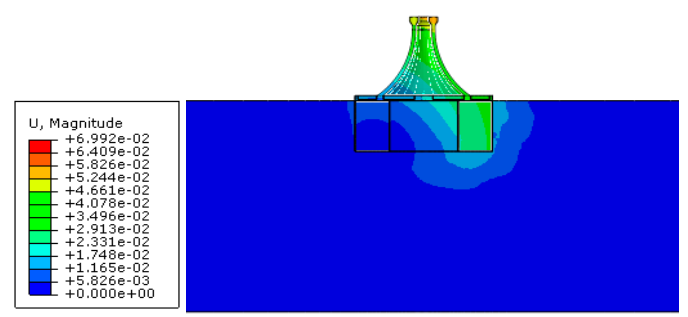

(b)

Figure 9. Displacement under ultimate load: (a) Line type; (b) Arc type.

\section{Analysis of the Load-Bearing Mode}

The CBF bucket has a diameter of $30 \mathrm{~m}$, and the insertion depth of bucket wall is about $12 \mathrm{~m}$; these are significantly different from those of traditional bucket foundations. The resistance of a bucket foundation under monotonous and combined load conditions mainly includes the front soil pressures inside and outside the bucket wall, the back soil pressures inside and outside the bucket wall, and the earth pressures on the top cover and separating plate. Therefore, the relationship between the upper structure form and the bearing mode requires further investigation. The height to diameter ratio of the bucket foundation is 0.4 , and the internal space of the bucket is divided into seven rooms by separating plates. According to [2], the separating plate is designed mainly for controlling the suction process; they can also provide safety reserves for the bearing capacity of CBF. Therefore, the effect of partition plates is not considered in the current calculation. Figure 10 shows all the distributions of the earth pressure on the top cover of arc- and line-type foundations under horizontal, vertical, and bending loadings. Figure 11 shows the soil pressure inside and outside the front bucket wall, whereas Figure 11 presents the back soil pressure inside and outside the bucket wall under monotonic loads along three directions

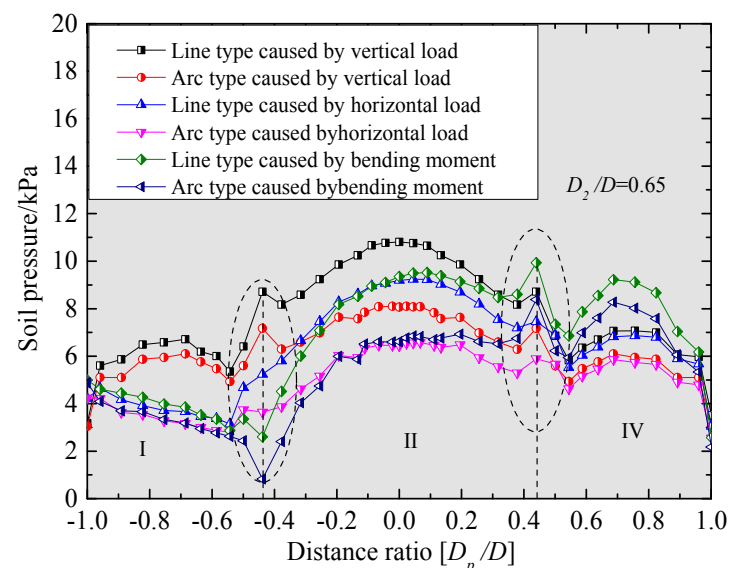

Figure 10. Top-cover soil pressure with monotonic load. 


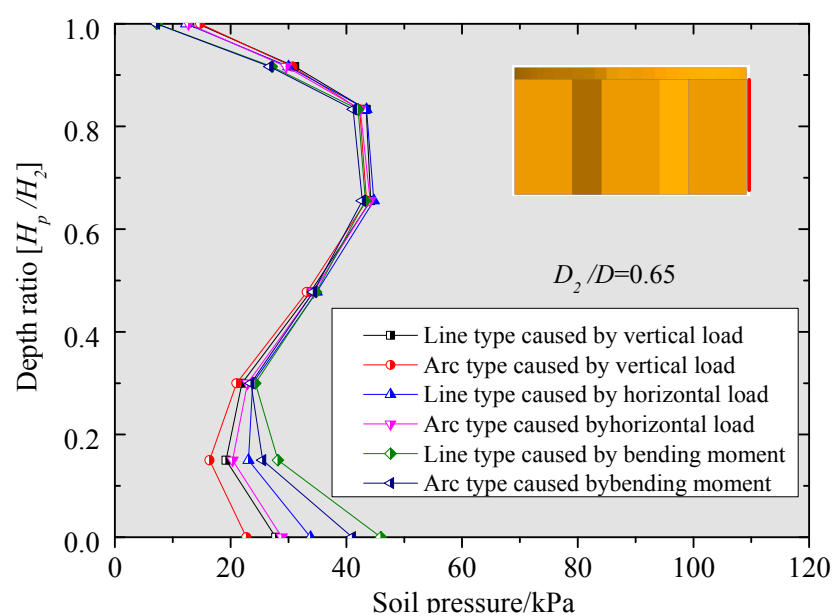

(a)

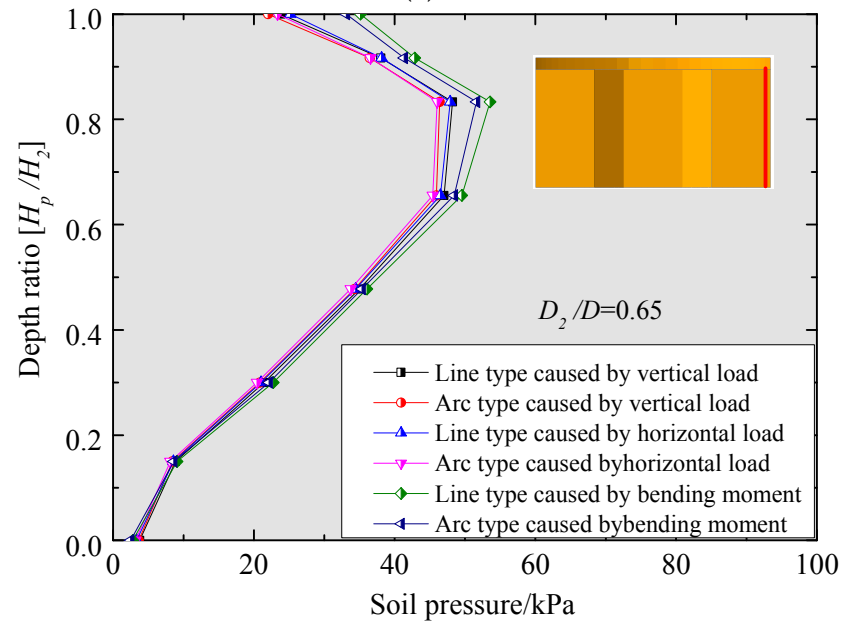

(b)

Figure 11. Soil pressures on the front bucket: (a) Outside skirt; (b) Inside skirt.

As can be seen from Figure 10, the earth pressure on two sides of the top cover center presents a symmetrical distribution under vertical load. The maximum soil pressure is relatively large near the center of the top lid, and two increasing points can be found at the location where the distance ratio is close to 0.4 . This can be mainly attributed to the fact that the upper structural load is transferred to the inner-ring beam on the top cover through the transition segment, and that the ring beam diameter is approximately $19 \mathrm{~m}$. Therefore, a significant amount of load is transferred to the annular region (I and III) between the inner- and outer-ring beam, and then distributed in the surroundings. Figure 9 also shows that the line-type foundation can bear more earth pressure than the arc one. The soil pressure distribution due to the bending moment and horizontal loads are roughly the same as that due to the vertical load. In the calculation results, the overall deformation of the foundation under the bending moment is a combined deformation of rotation and movement. Therefore, the calculation results in region I are reduced, and the soil pressure in region III significantly increase simultaneously. Overall, the soil pressure on the top lid of line-type foundation is greater than that of arc-type under monotonic load.

Figure 11 shows the soil pressures inside and outside the front bucket wall under the monotonic vertical, horizontal, and bending moment loads. As can be seen from Figure 11a, the external earth pressure along the front bucket wall of the two types of foundation shows the same S-shaped distribution under monotonic load. The maximum value is on the skirt top. Figure 11b illustrates the external earth pressure along front bucket wall, showing that it increases gradually from the skirt top and decreases close to bottom at a depth ratio of 0.7 . Figure 12 presents the soil pressure distribution 
inside and outside the back bucket wall. It can be seen that the regular soil pressure patterns on the back skirts are the same as those in the front bucket wall. This is because the inner and outer sides of the bucket are divided into a passive (in the direction of the load) and active region (in the opposite direction). In any case, the soil pressure of line-type is greater than that of arc-type. Therefore, the line-type foundation is capable of transferring more loads in the vertical, horizontal, and bending moment directions through its bucket wall.

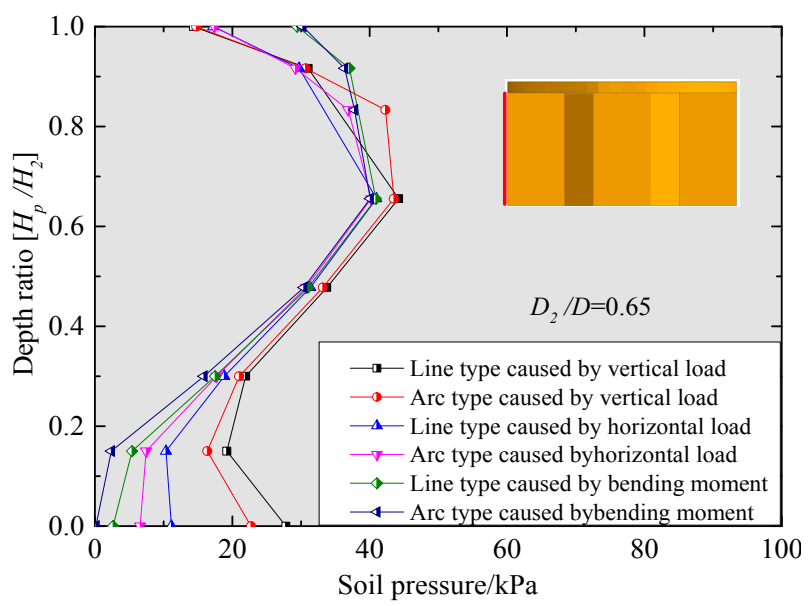

(a)

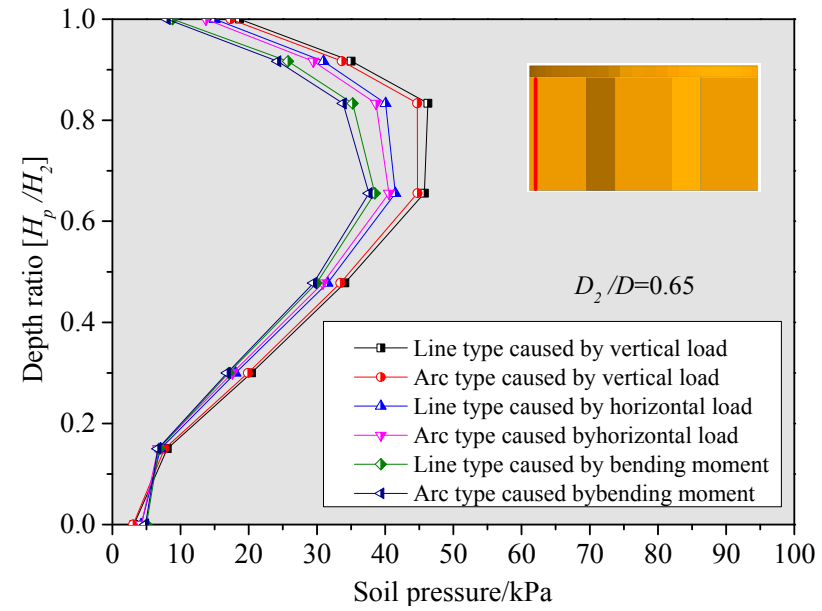

(b)

Figure 12. Soil pressures on the back bucket: (a) Outside skirt; (b) Inside skirt.

Figures 13-15 show the soil pressure distributions on the top lid and bucket wall of different foundation types under the ultimate load of a 50-year return period. As shown in Figure 13, the soil pressure distributions in regions I, II, and III undergo changes. Most of the soil pressure is located on the top lid along the direction of the load. The soil pressure is almost close to zero at the position where the distance ratio is 0.5 . This finding indicates that the soil inside the bucket lid is about to be disengaged with the top cover. The calculation results show that, under the ultimate load, the overall deformation of the two foundations is a combination of rotation and movement, as well as the bending moment. Moreover, the soil pressure on the top lid of the line-type foundation is greater than that of arc-type.

Meanwhile, Figure 14 reveals the soil pressures inside and outside the front bucket wall. As shown in Figure 14a, the external earth pressures along the front bucket wall of the two types of foundation types have an S-shaped distribution under the monotonic load. The soil pressures inside 
and outside the front bucket wall of line-type foundation are close to those of the arc-type. Hence, the distribution is consistent.

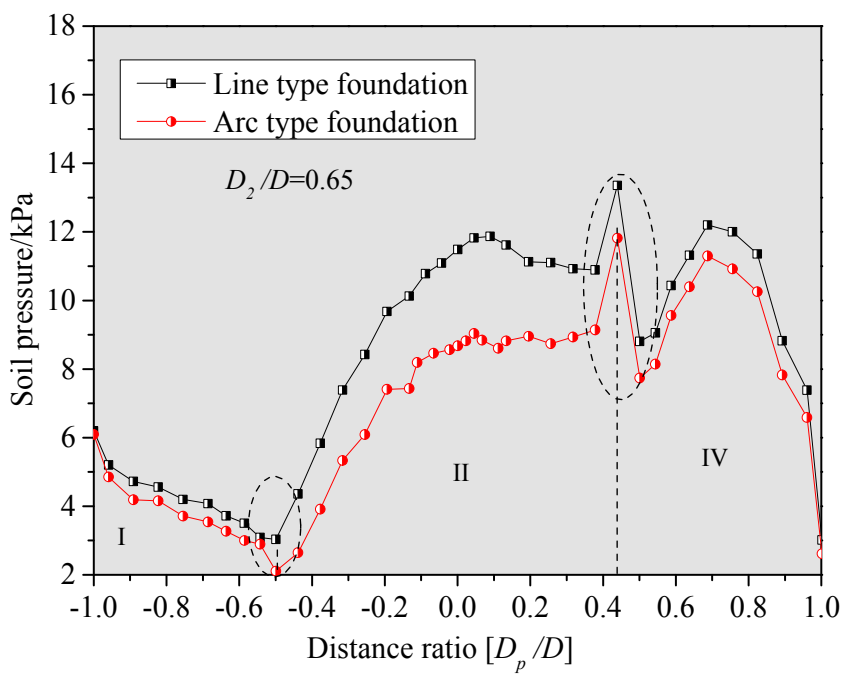

Figure 13. Top-cover soil pressure with ultimate load.

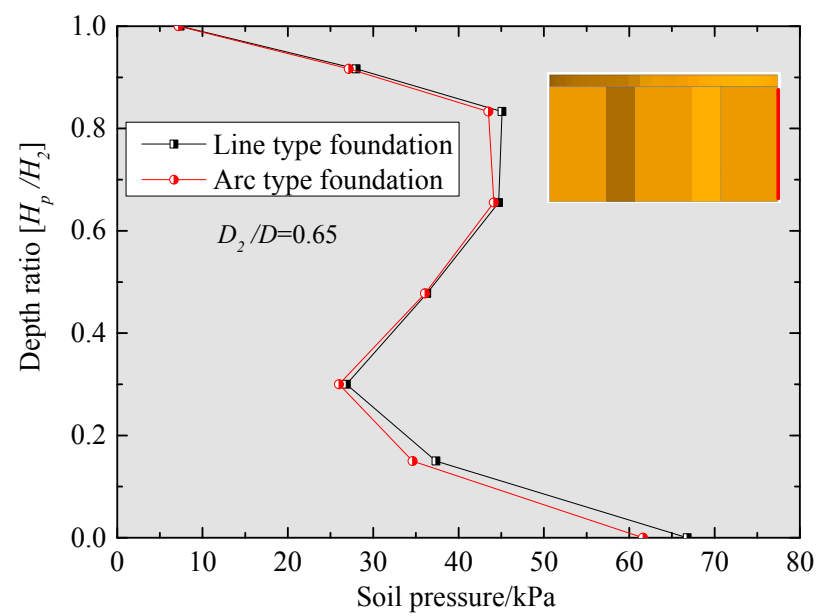

(a)

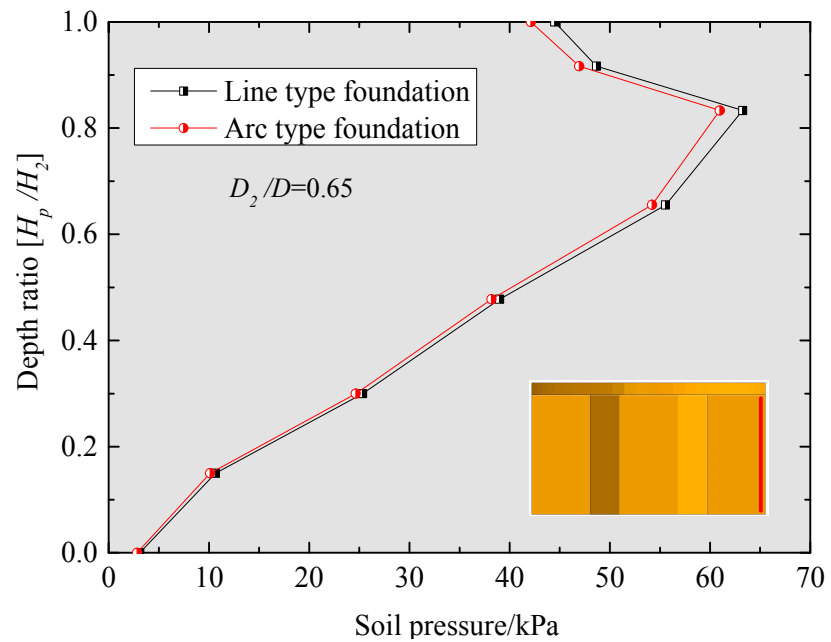

(b)

Figure 14. Soil pressures on the front bucket: (a) Outside skirt; (b) Inside skirt. 


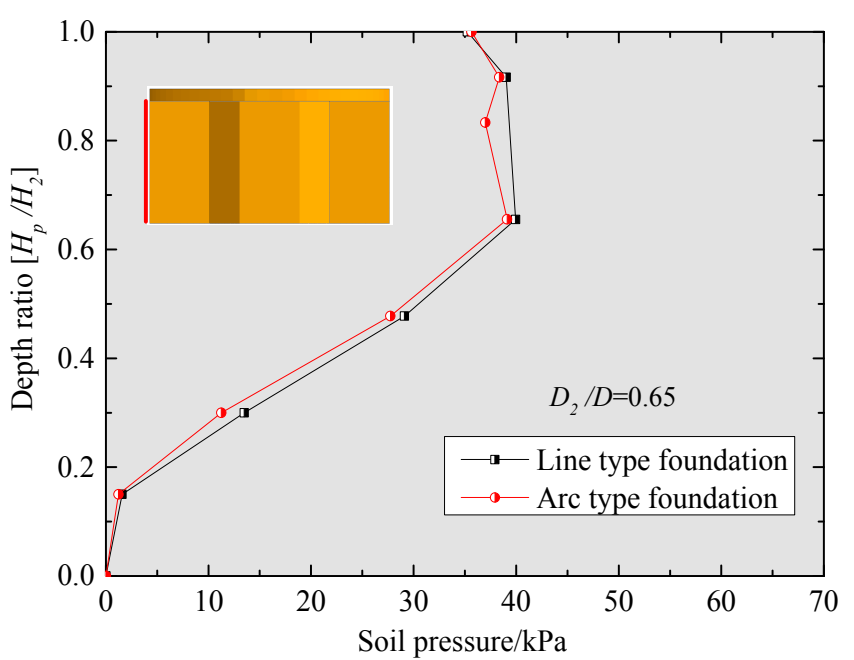

(a)

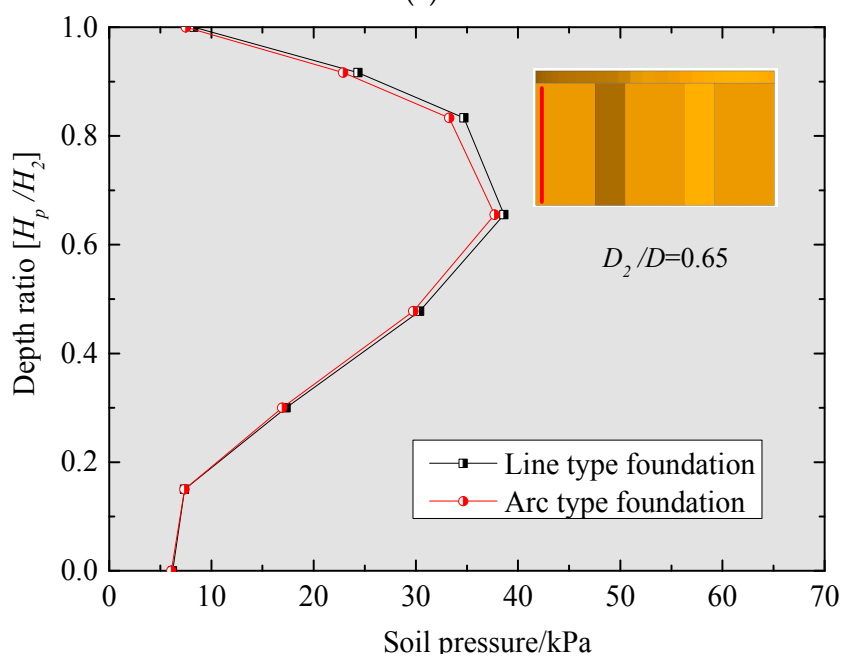

(b)

Figure 15. Soil pressures on the back bucket: (a) Outside skirt; (b) Inside skirt.

Figure 16 present the deformation vectors for the two types of foundation based on the FEA calculation result. Taking the bending moment load condition as an example, we can see that the deformations of both foundations are mainly rotational under bending moment load, and that the location of rotation center changes continually in the deformation process.

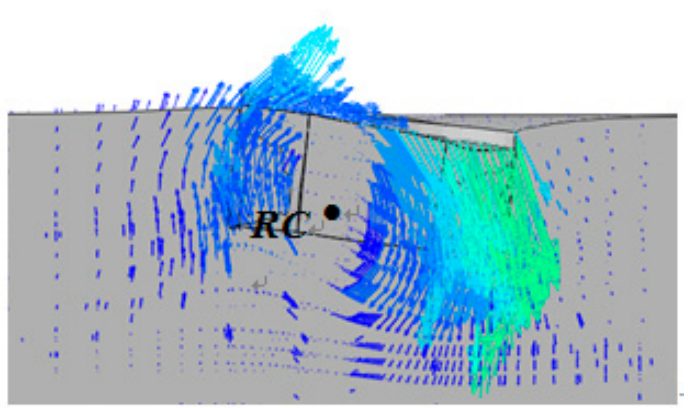

(a)

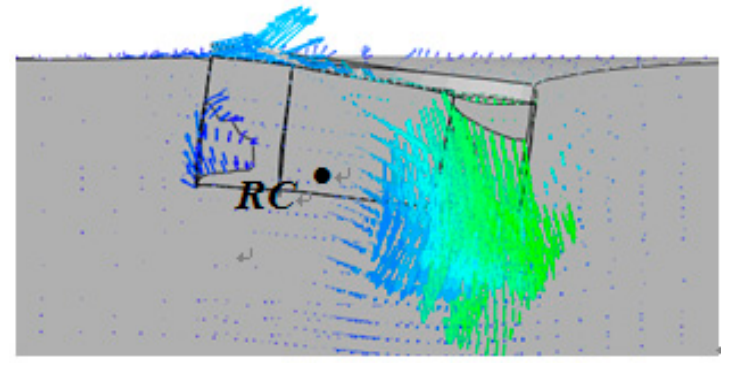

(b)

Figure 16. Rotational deformation of the foundation under bending moment load: (a) Arc type; (b) Line type. 
The location of rotation center is identified at the point that is located near and on the left side of the central axis of bucket foundation in the opposite direction of the load. The depth ratio of rotation center is approximately 0.65 times of that of the bucket wall height, and this can be set as shown in Figure 17.

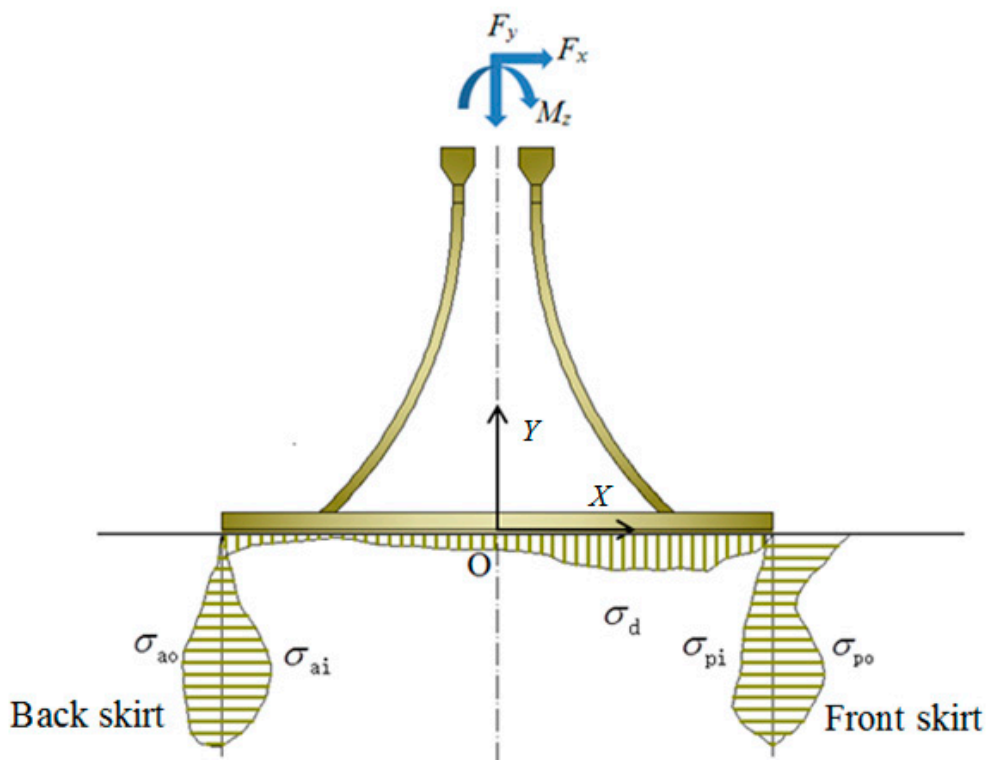

Figure 17. Soil pressure distribution of CBF under an ultimate load of a 50-year return period.

To further investigate the contribution ratio of each part of the bucket foundation and to identify the bearing mode of two types of CBF, the distribution characteristics of soil pressure on the top lid and on the front and back skirts are shown in Figure 17. It can be seen that larger soil pressures can be found on both sides of the front and back bucket walls. Moreover, the soil pressures on the skirts are in opposite directions; therefore, the soil pressure on bucket wall is extremely small after the counteraction. The structure is in a limit equilibrium state under the ultimate load of a 50-year return period. The resultant forces on the top cover and the bucket wall are calculated according to Equations (7)-(9), with results listed in Table 2.

Table 2. Load bearings of different parts.

\begin{tabular}{|c|c|c|c|c|c|c|}
\hline Foundation & Different Loading & $\begin{array}{c}\text { Soil Pressure } \\
\text { on Top Cover } \\
(\mathbf{k N})\end{array}$ & $\begin{array}{c}\text { Soil Pressure } \\
\text { on Back Skirt } \\
(\mathrm{kN})\end{array}$ & $\begin{array}{l}\text { Soil Pressure } \\
\text { on the Front } \\
\text { Skirt }(\mathbf{k N})\end{array}$ & $\begin{array}{c}\text { Friction } \\
\text { Resistance on } \\
\text { Back Skirt (kN) }\end{array}$ & $\begin{array}{c}\text { Friction } \\
\text { Resistance on } \\
\text { Front Skirt (kN) }\end{array}$ \\
\hline \multirow{3}{*}{ Line } & Vertical & 233.475 & 18.164 & 13.588 & 95.932 & 80.511 \\
\hline & Bending moments & 205.216 & 30.178 & 12.832 & 31.602 & 83.901 \\
\hline & $\begin{array}{c}\text { Ultimate load of a } \\
50 \text {-year return period }\end{array}$ & 253.150 & 12.101 & 12.549 & 24.889 & 82.157 \\
\hline \multirow{2}{*}{ Arc } & Bending moments & 161.388 & 22.790 & 9.653 & 21.265 & 79.918 \\
\hline & $\begin{array}{c}\text { Ultimate load of a } \\
50 \text {-year return period }\end{array}$ & 209.860 & 6.404 & 9.803 & 15.844 & 80.131 \\
\hline
\end{tabular}

The resultant forces on the front bucket wall, back bucket wall, and bucket top lid are respectively given by the following equations:

$$
F_{p}=\int\left(\sigma_{p o}-\sigma_{p i}\right) \mathrm{d} H=\int_{0}^{H}\left(\sigma_{p o}-\sigma_{p i}\right) \mathrm{d} H
$$




$$
\begin{gathered}
F_{a}=\int\left(\sigma_{a o}-\sigma_{a i}\right) \mathrm{d} H=\int_{0}^{H}\left(\sigma_{a o}-\sigma_{a i}\right) \mathrm{d} H \\
F_{d}=\int \sigma_{d} \mathrm{~d} R=\int_{0}^{R} \sigma_{d} \mathrm{~d} R
\end{gathered}
$$

where $H$ represents the height of bucket wall; $R$ represents the diameter of bucket; $\sigma_{p o}$ represents the soil pressure outside the front skirt; $\sigma_{p i}$ represents the soil pressure inside the front skirt; $\sigma_{a o}$ represents the soil pressure outside the back skirt; $\sigma_{a i}$ represents the soil pressure inside the back skirt; and $\sigma_{d}$ represents the soil pressure on the bucket top cover.

Ignoring the influence of the honeycomb partition plate, the bearing ratios of top cover to the front and back skirts under monotonic and ultimate load are listed in Table 3. It can be seen that under vertical and horizontal load conditions, the bearing proportion of the top cover of line-type is approximately $52 \%$, whereas that of arc-type is approximately $49 \%$. For the action of bending moment, the proportions are almost $56.4 \%$ and $54.7 \%$, and they can reach $65.8 \%$ and $65.2 \%$, respectively, especially under the condition of the ultimate load of a 50-year return period. Therefore, the top cover of CBF is the main part of load bearing with the bucket wall as its auxiliary. This means that the bearing mode of CBF is a "top-cover bearing". For the top lid bearing foundation, the above results are in accordance with the conclusion obtained in Sections 2 and 3, indicating that the line-type foundation conforms better to the design concept of $\mathrm{CBF}$ for offshore wind turbines in terms of the load-bearing mode of bucket top cover.

Table 3. Bearing proportions of different parts of the CBF.

\begin{tabular}{ccccc}
\hline Foundation & Different Loadings & Top Cover \% & Back Skirt \% & Front Skirt \% \\
\hline \multirow{3}{*}{ Line } & Vertical & 52.9 & 25.8 & 21.3 \\
& Horizontal & 52.6 & 16.5 & 30.9 \\
& Bending moments & 56.4 & 17.0 & 26.6 \\
& Ultimate load of a 50-year return period & 65.8 & 9.6 & 24.6 \\
\hline \multirow{3}{*}{ Arc } & Vertical & 49.1 & 29.4 & 21.5 \\
& Horizontal & 49.1 & 17.1 & 33.8 \\
& Bending moments & 54.7 & 14.9 & 30.4 \\
& Ultimate load of a 50-year return period & 65.2 & 6.9 & 27.9 \\
\hline
\end{tabular}

\section{Analysis of the Curvatures of Different Arc Type Foundations}

From the above analysis, we can see that the upper structural type of transition section significantly affects the distribution of soil pressure on the top lid but not on the bucket skirt. The bearing capacity of two foundation types tends to converge substantially on the bucket skirt under the combined and monotonous load conditions, without a significant difference. For an arc transition section, the structure type is determined by the curvature radius, which is related to the ratio between $D_{2}$ and $D$. Hence, the arc transition section with a different curvature radius can affect the force transfer and bearing mode.

In this section, FEM is established to determine the impact of curvature radius on the top cover bearing mode of the arc-type bucket foundation. Figure 18 presents the distribution of soil pressure on the bucket top lid of the arc-type foundation with different curvature radii. Figure 19 present the skin friction distributions outside and inside the back bucket wall. Figure 20 presents the skin friction distributions on the front bucket walls of different arc foundations.

As shown in Figure 18, the curvature of arc-type transition section has certain effects on the top cover load-bearing mode. The earth pressure on the top lid increases with the increase of diameter ratio, and decreases when the ratio is larger than 0.65 . This finding means that the top lid bears more loads when $D_{2} / D$ is 0.65 . Meanwhile, we can see from Figure 19 that the regular pattern of skin friction on the back skirt is the same as those on the front bucket wall; moreover, the skin friction increases gradually from skirt top to a depth ratio of 0.65 , and decreases from this depth ratio to the skirt bottom. The maximum value of skin friction is also obtained when $D_{2} / D$ is 0.75 . Figure 20 reveals that the skin 
friction is larger outside the bucket wall than that inside the bucket wall. For the arc-type, the change of skin friction on the back bucket wall is not obvious with the enlarged diameter ratio $D_{2} / D$.

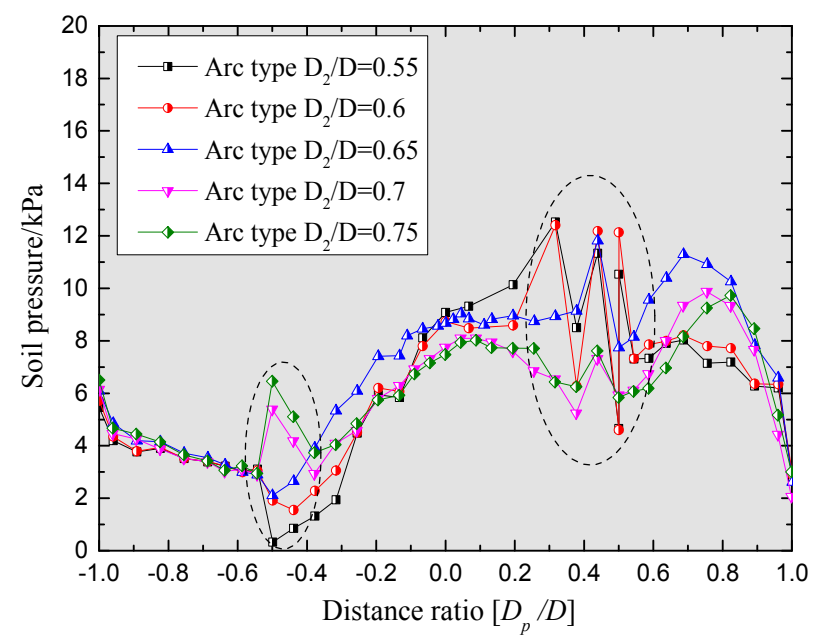

Figure 18. Soil pressure on the top cover.

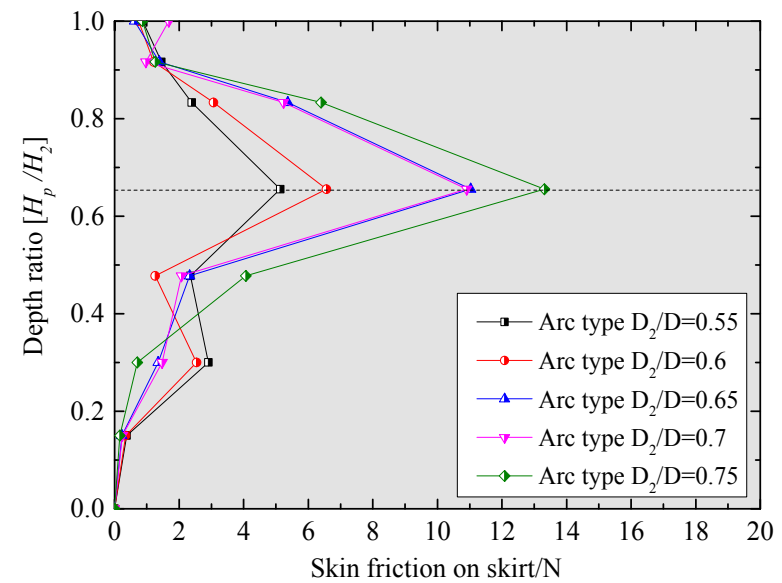

(a)

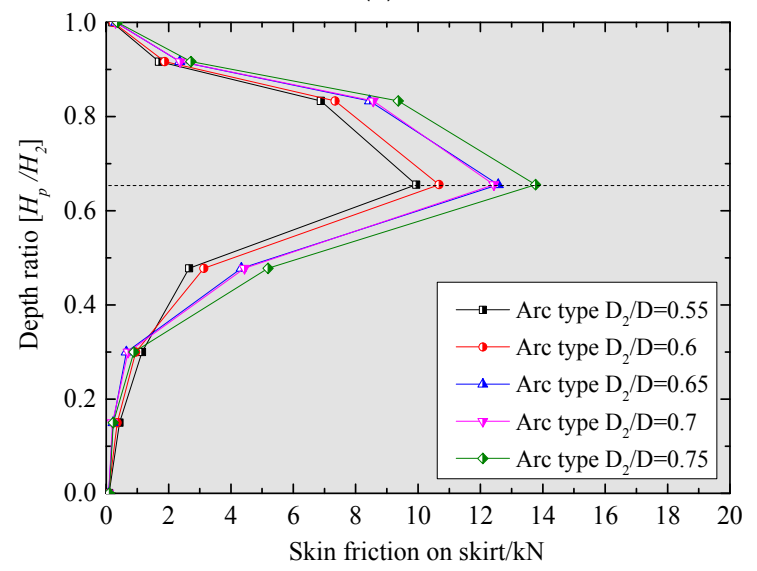

(b)

Figure 19. Skin friction on the back bucket: (a) Outside skirt; (b) Inside skirt. 


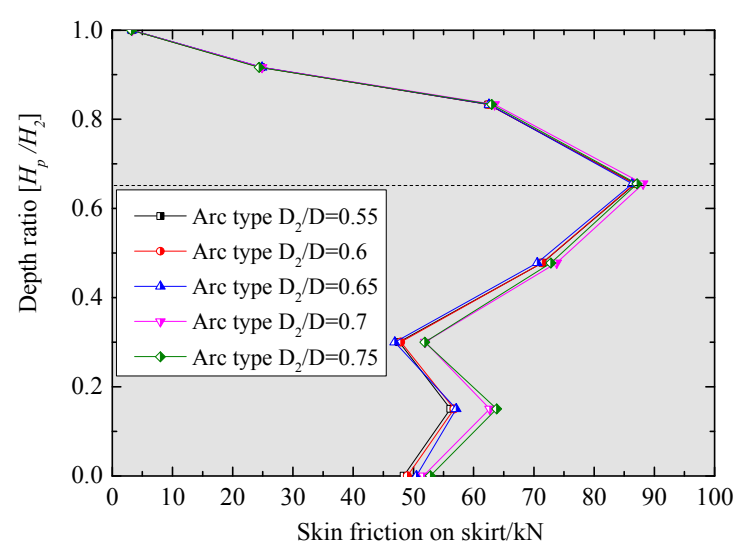

(a)

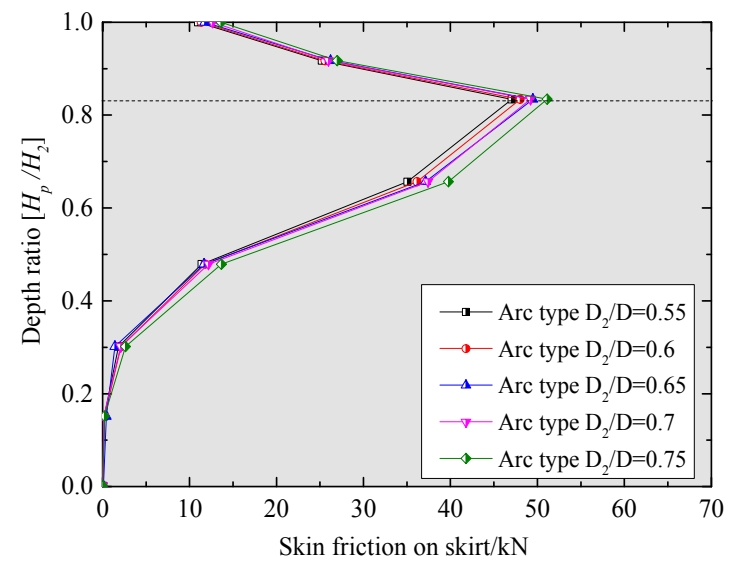

(b)

Figure 20. Skin friction on front bucket: (a) Outside skirt; (b) Inside skirt.

The above results can be explained as follows. The force transfer function of top cover is gradually attenuated when the margin of transition section extended to that of the bucket wall; meanwhile, the upper load is directly transferred to the bucket wall margin through the transition segment. These findings indicate that the maximum utilization ratio of the bucket top lid is reached when $D_{2} / D$ is 0.7. When $D_{2} / D$ is less than 0.7 , the transition segment is not extended to the edge of the bucket; instead, the load is transferred to the top cover with the transition section, and further to the bucket wall margin.

Compared with the above results shown in Section 4, the structural type of the upper transition structure must be closely associated with the force transfer and load-bearing mode of CBF. Moreover, the line-type structure outperforms the arc-type at the same ratio; hence, the effect of $D_{2} / D$ can be considered negligible. Consequently, optimizing the structural type is critical to the foundation design. The arc-type could preferably convert the load and control cracking through an arch force transfer pathway. However, according to the design concept of the bucket foundation with the top cover force bearing, the line-type transition section must have a thicker top cover to transfer the load to the subgrade.

\section{Conclusions}

In this paper, we investigated the force transfer characteristics, load-bearing and failure mode of two types of foundations, as well as the bearing proportion of each part of two transition structures of the innovative pre-stressed CBFs for offshore wind turbines. Furthermore, the force transfers of arc-type foundations with different curvatures were measured. The main conclusions are summarized below: 
- Through finite element calculation, we find that the line- and arc-type structures have significantly different force transfer characteristics. The pre-stressed line-type has better performance in terms of load bearing than the arc one, and the former can maintain a lower stress level in most cross-sections throughout the entire transition segment, except the top section. Meanwhile, the arc structure can gradually diffuse and distribute the stress along the height and circumferential direction, thus avoiding stress concentration in any cross-section throughout the entire transition section. Both the transition section can gradually transfer the huge bending moment load at the upper structure of the turbine downwards with the pre-stressed tendons, until they become relatively small and further changes into controllable tensile and compressive stresses. However, the section area of line-type is larger than the arc one at the same height, which is a disadvantage for resisting wave force according to the wave diffraction theory.

- The top cover of CBF can be considered as the main part with a load-bearing function, with the bucket wall as auxiliary, meaning that the bearing mode of CBF is "top cover bearing". For the top lid bearing foundation, the line-type foundation conforms better to the design concept of CBF for offshore wind turbines.

- The structural type of the upper transition structure must be closely associated with the force transfer and the load-bearing mode of CBF. Moreover, the line-type structure outperforms the arc-type at the same ratio, thus the effect of $D_{2} / D$ is negligible. Consequently, optimizing the structural style is critical to the foundation design. The line-type could preferably convert the load and control the cracking through an arc force transfer pathway. However, according to the design concept of the bucket foundation with top cover force bearing, the line-type transition section requires a thicker top cover to transfer the load to the subgrade.

Acknowledgments: The authors would like to acknowledge the support from the National Natural Science Foundation of China (Grant Nos. 51379142 \& 51679163), Innovation Method Fund of China (Grant No. 2016IM030100) and the Tianjin Municipal Natural Science Foundation (Grant No. 17JCYBJC22000).

Author Contributions: Hongyan Ding, Puyang Zhang and Shaohua He conceived and designed the experiments; Shaohua He and Puyang Zhang performed the experiments; Shaohua He and Puyang Zhang analyzed the data; Hongyan Ding and Puyang Zhang contributed reagents/materials/analysis tools; Shaohua He, Puyang Zhang and Hongyan Ding wrote the paper.

Conflicts of Interest: The authors declare no conflict of interest.

\section{References}

1. Helfrich, S.; Brazill, R.; Richards, A. Pullout characteristics of a suction anchor in sand. In Proceedings of the Offshore Technology Conference, Houston, TX, USA, 3-6 May 1976.

2. Le, C.H.; Sung, R.K. Evaluation of vertical and horizontal bearing capacity of bucket foundations in clay. Ocean Eng. 2012, 52, 75-82.

3. Barari, A.; Ibsen, L.B. Undrained response of bucket foundations to moment loading. Appl. Ocean Res. 2012, 36, 12-21. [CrossRef]

4. Park, J.-S.; Park, D.; Yoon, S.-W.; Jang, H.S. Vertical load transfer mechanism of bucket foundation in sand. J. Korean Geotech. Soc. 2015, 31, 29-39. [CrossRef]

5. Kim, S.; Yun, W.K.; Kim, D.-S. Pullout capacity of horizontally loaded suction anchor installed in silty sand. J. Mar. Georesour. Geotech. 2016, 34, 87-95. [CrossRef]

6. Vahdatirad, M.J.; Diaz, A.T.; Nielsen, S.; Ibsen, L.B.; Andersen, L.V.; Firouzianbandpey, S.; Griffiths, D.V. A load-displacement based approach to assess the bearing capacity and deformations of mono-bucket foundations. In Proceedings of the Sixth International Conference on Structural Engineering, Mechanics and Computation, Cape Town, South Africa, 5-7 September 2016.

7. Lian, J.J.; Ding, H.Y.; Zhang, P.Y.; Yu, R. Design of large-scale prestressing bucket foundation for offshore wind turbines. Trans. Tianjin Univ. 2012, 18, 79-184. [CrossRef] 
8. Zhang, P.Y.; Ding, H.Y.; Zhai, S.H. Test on muddy soil reinforcement by negative pressure and electro-osmosis inside cover-bearing-type bucket foundation for offshore wind turbines. Trans. Tianjin Univ. 2013, 19, 010-016. [CrossRef]

9. Li, D.Y.; Zhang, Y.K.; Feng, L.Y. Capacity of modified suction caissons in marine sand under static horizontal loading. Ocean Eng. 2015, 102, 1-16. [CrossRef]

10. Liu, M.M.; Yang, M.; Wang, H.J. Bearing behavior of wide-shallow bucket foundation for offshore wind turbines in drained silty sand. Ocean Eng. 2014, 82, 169-179. [CrossRef]

11. Ding, H.; Liu, Y.; Zhang, P.; Le, C. Model tests on the bearing capacity of wide-shallow composite bucket foundations for offshore wind turbines in clay. Ocean Eng. 2015, 103, 114-122. [CrossRef]

12. Liu, R.; Chen, G.; Lian, J.; Ding, H. Vertical bearing behaviour of the composite bucket shallow foundation of offshore wind turbines. J. Renew. Sustain. Energy 2015, 7, 013123. [CrossRef]

13. Zhang, P.Y.; Ding, H.Y.; Le, C.H. Model tests on tilt adjustment techniques for a mooring dolphin platform with three suction caisson foundations in clay. Ocean Eng. 2013, 73, 96-105. [CrossRef]

14. Zhang, P.Y.; Ding, H.Y.; Le, C.H. Installation and removal records of field trials for two mooring dolphin platforms with three suction caissons. J. Waterw. Port Coast. Ocean Eng. 2013, 139, 502-517. [CrossRef]

15. Ding, H.Y.; Lian, J.J.; Li, A.D.; Zhang, P.Y. One-step-installation of offshore wind turbine on large-scale bucket-top-bearing bucket foundation. Trans. Tianjin Univ. 2013, 19, 188-194. [CrossRef]

16. Lian, J.J.; Sun, L.Q.; Zhang, J.F.; Wang, H.J. Bearing capacity and technical advantages of composite bucket foundation of offshore wind turbines. Trans. Tianjin Univ. 2011, 17, 132-137. [CrossRef]

17. Liu, R.; Zhou, L.; Lian, J.J.; Ding, H.Y. Behavior of monopile foundations for offshore wind farms in sand. J. Waterw. Port Coast. Ocean Eng. 2016, 142, 04015010. [CrossRef]

18. Zhang, P.Y.; Ding, H.Y. Bearing capacity of the bucket spudcan foundation for offshore jack-up drilling platforms. Pet. Explor. Dev. 2011, 38, 237-242. [CrossRef]

19. Zhang, P.Y.; Han, Y.Q.; Ding, H.Y.; Zhang, S.Y. Field experiments on wet tows of an integrated transportation and installation vessel with two bucket foundations for offshore wind turbines. Ocean Eng. 2015, 108, 769-777. [CrossRef]

20. Zhang, Y.K.; Gao, Y.F.; Li, D.Y.; Mahfouz, A.H. H-M bearing capacity of a modified suction caisson determined by using load-/displacement-controlled methods. China Ocean Eng. 2016, 30, 926-941. [CrossRef]

21. Wu, K.; Fan, Q.L. Study on bearing capacity of bucket foundation subjected to horizontal loading. J. Coast. Res. 2015, 73, 511-515. [CrossRef]

22. Zhang, P.; Ding, H.; Le, C. Hydrodynamic motion of a large prestressed concrete bucket foundation for offshore wind turbines. J. Renew. Sustain. Energy 2013, 5, 477-488. [CrossRef]

23. Liu, Y.G.; Zhang, P.Y.; Ding, H.Y.; Zhang, Z. Load bearing characteristics of composite bucket foundation for offshore wind turbines. J. Mar. Sci. Technol. 2016, 24, 790-797. 